\title{
0 Melhor Governo Possível: Francesco Guicciardini e o Método Prudencial de Análise da Política*
}

\author{
Felipe Charbel Teixeira
}

"Alcançam fins vãos ou a superfície das coisas aqueles que, sem leitura ou experiência, não possuem olhos penetrantes. [...]. Não te deves comover com as coisas vãs que comovem os outros, mas somente com a razão verdadeira, sólida e fundada nas coisas" (Francesco Guicciardini. Consolatoria, tradução do autor).

\section{O MELHOR GOVERNO POSSÍVEL}

$\mathrm{Q}$ uando a Península Itálica se encontrava à mercê das tropas francesas e espanholas, na primeira metade do século XVI, o Renascimento italiano mostrava seus últimos sinais de brilho. No que diz respeito à reflexão política, dois nomes podem ser mencionados, dentre vários que se destacaram no cenário florentino, especialmente pela repercussão póstuma de seus escritos: Nicolau Maquiavel (1469-1527) e Francesco Guicciardini (1483-1540). Do primeiro ficaram várias ima-

\footnotetext{
*Este artigo corresponde a parte de minha dissertação de mestrado - A República Bem Ordenada: Francesco Guicciardini e a Arte do Bom Governo --, defendida em 2004 no Programa de Pós-Graduação em História Social da Cultura da Pontifícia Universidade Católica do Rio de Janeiro - PUC-Rio, com a orientação do prof. Marcelo Gantus Jasmin. Agradeço aos professores Newton Bignotto e Cesar Guimarães pelos comentários e sugestões durante a argüição. Este estudo contou com auxílio financeiro do Conselho Nacional de Desenvolvimento Científico e Tecnológico - CNPq e da Coordenação de Aperfeiçoamento de Pessoal de Nível Superior - Capes.
}

DADOS - Revista de Ciências Sociais, Rio de Janeiro, Vol. 50, n-2 2, 2007, pp. 325 a 349. 
gens, que vão do escritor maldito ao defensor ferrenho da liberdade republicana; o Príncipe e os Discorsi estão entre os textos mais debatidos e comentados do Ocidente, sendo mobilizados, lidos e reinterpretados desde que chegaram pela primeira vez ao grande público. O segundo não teve suas obras tão vulgarizadas quanto seu conterrâneo; ainda assim, desde 1561 - data da primeira publicação da Storia d'Italia -, seu nome tornou-se sinônimo do relato mais agudo da crise da Península Itálica no século XVI, e por que não dizer da crise dos valores que caracterizaram a Renascença.

Pode-se afirmar que o "historiador Guicciardini" ficou conhecido antes do "analista político": apenas em meados do século XIX, seus opúsculos anteriores a 1527 foram redescobertos (Ridolfi, 1967:272). Os "papéis secretos" de Guicciardini, conservados por mais de 300 anos em um "baú" familiar, foram publicados por Giuseppe Canestrini entre 1857 e 1867 em diversos volumes. Deles constavam textos até então inéditos, como o Discorso di Logrogno, o Dialogo del Reggimento di Firen$z e$, as várias versões dos Ricordi, as Considerazioni sopra i discorsi del Machiavelli, as Storie Fiorentine, entre outros.

Contemporâneo e interlocutor de Maquiavel, Francesco Guicciardini compartilhava com o amigo o apego à prática política e aos valores do vivere civile. Consideravam-se prudentes, homens dotados de extrema sabedoria prática, discretos conhecedores da arte do estado - conjunto de preceitos empíricos associados à condução da res publica ou de um stato principesco, os quais visavam a manutenção e ampliação dos seus domínios (Viroli, 1992:180). Como nota Mario Santoro, ambos se mostravam concordantes com as lições do humanista napolitano Giovanni Pontano acerca da necessidade de uma análise mais apurada da realidade e das suas condições determinantes, como as motivações particulares dos agentes políticos e as disposições naturais do ser humano (Santoro, 1978:170). Diz Guicciardini (1994:33, tradução do autor), em passagem do Dialogo del Reggimento di Firenze: "se quisermos tecer juízos sobre um governo ou outro, não devemos considerar tanto de que espécies sejam, mas os efeitos deles". Tal análise efeitual, contudo, não implica uma rejeição dos preceitos clássicos do bom governo - concórdia, liberdade, justiça e harmonia, tornadas possíveis pela condução virtuosa da res publica. Em seus textos, especialmente no Dialogo, Guicciardini debate ativa e criticamente com as tradições filosóficas antiga e humanista (Bignotto, 2006:129), agregando aos valores tradici- 
onais do bom governo um convite ao exame atento das "coisas do mundo" e dos efeitos particulares das ações políticas.

Tanto Maquiavel quanto Guicciardini procuravam discorrer, em muitos dos seus textos, sobre o emprego de meios capazes de incidir com eficiência na atenuação ou reversão dos processos de corrupção dos costumes e degradação dos valores republicanos que, segundo eles, assolavam a Península Itálica nas primeiras décadas do século XVI. Nota-se, nesse sentido, uma guinada teórica em relação aos autores quatrocentistas - os "humanistas cívicos", segundo denominação proposta por Hans Baron ${ }^{1}$. No caso específico de Guicciardini, a busca pela "efetividade" analítica revela-se o alicerce de um procedimento prudencial fundado na idéia metafórica do olhar penetrante e agudo: na medida em que possuam tal predicado - formado pela associação entre prudência natural, experiência prática e leitura cuidadosa das "histórias antigas e modernas" -, o governante e o analista se habilitam a discorrer com alguma precisão sobre as vicissitudes das "coisas do mundo", mostrando-se capacitados a estabelecer juízos políticos seguros sobre a realidade e suas transformações. Delineia-se, assim, uma teoria da ação política, calcada tanto no exame dos interesses e motivações permanentes dos homens - "substância das coisas" - quanto na observação das diversas contingências próprias das escolhas particulares e movimentos eventuais - os accidenti, dominados pela Fortuna. Esta teoria tem por objetivos: (a) a tentativa de antecipação dos efeitos das ações de príncipes e condutores de Repúblicas, com vistas à delimitação das escolhas pertinentes a serem tomadas pelo governante prudente; (b) definir os procedimentos adequados a uma reforma política e moral da cidade de Florença.

Conquanto demonstrasse profundo apego aos princípios habituais do bom governo, a relação de Guicciardini com a tradição filosófica antiga e humanista adquiria quase sempre contornos críticos, pois a flexibilidade moral necessária à efetividade analítica do prudente muitas vezes se chocava com a rigidez dos preceitos sustentados pelas autoridades clássicas, ou então com os valores cívicos arraigados entre os assim chamados ottimati florentinos. Como reformar eficientemente o reggimento (governo) de Florença, tornando-a apta a participar adequadamente dos jogos diplomáticos europeus, sem que os valores republicanos fossem assolados pelo estabelecimento de um regime tirânico? Como lidar com o predomínio mediceu - logo, com a redução a patamares mínimos da liberdade, segundo ele natural à cidade de Flo- 
rença (Guicciardini, 2000a:8) - e ainda assim manter viva ao menos a "sombra" de um governo livre? (Guicciardini, 2000c:64). Sustento que, em seus escritos políticos, Guicciardini procura equilibrar e conciliar os valores fundamentais do bom governo com a defesa dos preceitos empíricos da arte do estado, de modo a ressaltar a possível complementaridade entre ações estratégicas que busquem resultados eficientes e os valores fundamentais, coletivamente compartilhados e estabelecidos, de uma República bem-ordenada: em suma, um melhor governo possível $^{2}$.

É plausível estabelecer uma aproximação heurística entre as reflexões do escritor florentino e a filosofia prática aristotélica: na busca do equilíbrio entre uma moral ideal e as possibilidades efetivas do agir, Aristóteles parte da observação dos próprios desígnios que os agentes se impõem, de suas condutas e motivações, no sentido de delimitar os bens por eles almejados (Wolff, 2001:43). De acordo com o estagirita, "já que o termo 'bem' tem tantas acepções quanto 'ser' [...] obviamente ele não pode ser algo universal, presente em todos os casos e único" (Aristóteles, 1985, livro I, parte 1.096a). Do mesmo modo, o bom governo, em Guicciardini, não pode desconsiderar as "condições dos tempos" e as especificidades de uma determinada cidade e seus habitantes. Por esta razão, o novo tratamento conferido à questão da prudência revela-se o elemento-chave para a fundamentação de uma análise política aguda e penetrante, apropriada a uma reflexão sobre os rumos da República que tome por base tanto os valores fundamentais que os homens estabelecem para si mesmos - sendo a liberdade, entendida como ausência de dominações externas e capacidade de autodeterminação política (Pettit, 1997:51-79), o princípio mais importante no caso dos florentinos-, como também as vicissitudes e contingências de um tempo particularmente refratário a tais preceitos, tempo este que exige dos analistas e dos governantes celeridade decisória e profunda visão do complexo movimento das "coisas do mundo".

\section{AS TRADIÇÕES DO BOM GOVERNO E A QUESTÃO DA PRUDÊNCIA}

Antes de passar ao exame do conceito de prudenzia em Guicciardini, traçarei um brevíssimo panorama sobre a gênese e consolidação da idéia de bom governo na Península Itálica.

Entre 1337 e 1339, o artista Ambrogio Lorenzetti pinta, na Sala dei Nove do palácio público de Siena, um afresco composto de representações 
dos princípios gerais envolvidos no bom ordenamento de uma República; embora não fosse seu nome original, a pintura logo passa a ser conhecida como buon governo, e assim ganha notoriedade (Skinner, 2002:39). Os painéis tematizam preceitos éticos presentes em muitos tratados políticos dos séculos XII e XIII, como os de Brunetto Latini e Orfino da Lodi, dando especial destaque à liberdade, justiça, temperança e concórdia. Para que estas pudessem se concretizar, exigia-se dos governantes a observância das virtudes cardeais, principescas e cristãs (Skinner, 1999:146-149). As primeiras - justiça, prudência, fortaleza e temperança - diziam respeito ao equilíbrio moral do cidadão, enquanto as virtudes principescas - magnanimidade, honestidade e liberalidade - referiam-se à maneira correta de conduzir a República. Aliavam-se a estas as virtudes cristãs, imperativas em relação a todos os seres humanos.

Ainda que a expressão tenha surgido nos séculos finais da Idade Média, pode-se dizer que as pedras angulares do bom governo remetem ao tipo de consideração dos assuntos políticos instaurado pelas filosofias platônica e aristotélica. Em primeiro lugar, pode-se destacar a fundamentação positiva da finalidade última da vida coletiva. Contrariamente à "ética das obrigações", típica da modernidade - calcada nas noções de dever e obrigação, cumprimento dos deveres e respeito aos direitos alheios, fundamentadas utilitariamente ou deontologicamente -, o bom governo se alicerça em uma "ética das virtudes", em que as finalidades as quais os homens se impõem só podem ser realizadas plenamente através da perseguição de um fim último, necessariamente mais elevado que os objetivos egoístas: o bem comum (Eisenberg, 2003:79). As motivações dos agentes devem visar ao interesse coletivo; para tanto, os cidadãos - sobretudo os governantes - necessitam de um forte aparato moral, para que suas ações não se orientem exclusivamente pela inclinação a propósitos individuais. Para que o bem comum pudesse ser alcançado, tanto Platão quanto Aristóteles defendiam o imperativo do equilíbrio, não só entre os diversos setores e grupos que compunham a pólis, como também - e fundamentalmente-o controle e equilíbrio dos apetites individuais. Haja vista o caráter excepcional de uma pólis cujos membros fossem predominantemente virtuosos - a ideal superposição entre ética e política -, valorizava-se sobremaneira a virtude do governante, porquanto se entendia que este, ao realizar ações virtuosas, contribuía decisivamente para a solidificação do bem comum. Com vistas à condução correta da cidade, o governante deveria possuir uma série de aptidões e habilidades específicas. No trato 
dos assuntos públicos, a prudência - phrónesis ou prudentia - mostrava-se a virtude mais importante, isto em autores os mais diversos, como Platão, Aristóteles, Cícero, Tomás de Aquino e Marsílio de Pádua.

Para Platão, a phrónesis articula um tipo de ciência da política - politiké epistème, como define na República - subordinada à sabedoria filosófica (sophia). Já no Político, Platão (1980) tratará a política como uma tékhne. Como nota Pierre Aubenque (1986), a discordância acerca do exato papel da phrónesis constitui um dos elementos centrais da crítica de Aristóteles ao seu mestre. Para o estagirita, a phrónesis não poderia ser considerada um tipo de episteme ou tékhne, mas deveria ser tratada como disposição da alma racional - virtude intelectual -, voltada para a ação no mundo (MacIntyre, 2001:105). Ademais, Aristóteles ressalta que o reconhecimento do phrónimos - o homem prudente - é anterior à sua própria definição: este é apontado consensualmente por sua sabedoria prática e não, como em Platão, pela sabedoria filosófica (Aubenque, 1986:35). Ainda assim, pode-se dizer que os dois modelos apresentam um núcleo comum, exatamente a busca da melhor vida possível, modelada a partir da perseguição de uma vida ideal - o que, em Platão, é mais evidente nas Leis e no Político que propriamente na República.

Esta forma de conceber a política teve forte sedimentação entre os autores latinos, especialmente Cícero. E foi através do resgate de seus textos - juntamente com as obras de Salústio, Sêneca, Quintiliano, Tito Lívio, entre outros, e também o Digesto compilado no período de Justiniano - que a tradição do bom governo se solidificou na Península Itálica. Tais autoridades eram mobilizadas notadamente como alicerces para a legitimação do autogoverno nas pequenas repúblicas, contra as pretensões centralizadoras do Sacro Império (Skinner, 2002:13). Como não poderia deixar de ser, o conceito de prudentia, tão importante nos escritos ciceronianos, passa a ser amplamente destacado nos tratados humanistas. Para Cícero, a prudentia consiste na principal dentre as virtudes, uma vez que se responsabiliza pela adequação da ação singular ao princípio máximo da justiça: "a prudência, sem a justiça, é impotente para gerar a fé [...] sem a justiça, a prudência não terá força alguma" (Cícero, 1999, livro II, §34). Os "humanistas cívicos" de maior renome - Salutati, Bruni, Palmieri etc. - mantiveram este entendimento em seus tratados. Em Guicciardini, a prudenzia preserva sua centralidade, com uma novidade, porém, que altera significativamente o conceito: ela é tratada como a disposição responsável pelo exame acurado das "coisas do mundo", procedimento capaz de orientar estrategicamente 
as ações dos agentes políticos, sem necessariamente subsumi-las à justiça ou a qualquer outra virtude - tal reconsideração do conceito de prudentia a partir da interpretação dinâmica e problemática da existência humana, iniciada em fins do século XV pelo humanista Giovanni Pontano (Santoro, 1978:45), alcança seu apogeu na Florença da primeira metade do século XVI, especialmente nas reflexões de Maquiavel e Guicciardini.

\section{"DISCREZIONE" E AGUDEZA NO DISCURSO POLÍTICO DE GUICCIARDINI}

Francesco Guicciardini considerava-se um personagem ativo no jogo político italiano, e de fato o era. Ao longo de sua vida, foi nomeado para os cargos mais significativos da cidade de Florença. Serviu aos Medici durante muitos anos, quando estes ocupavam o papado com Leão X e Clemente VII; indicado por eles, governou cidades importantíssimas, como Parma, Reggio, Módena e Bolonha, além de ter sido presidente da Romanha e lugar-tenente papal em vários conflitos. A experiência acumulada se faz ver em seus textos, que têm quase sempre por objeto a discussão do melhor reggimento para a cidade de Florença e a busca das maneiras adequadas de consolidar, em conjunturas turbulentas e na medida do possível, os valores tradicionais do bom governo - o que, segundo ele, só seria possível através de um exame agudo da realidade. Apenas os prudentes - donos de olhos penetrantes, discrezione, experiência e conhecimento das "histórias antigas e modernas" - mostravam-se aptos a estabelecer, através da separação analítica entre "diversidades substanciais" e accidenti, juízos eficientes acerca da ação política e da reforma das leis. Diz Guicciardini, em carta de 18 de maio de 1521 destinada a Maquiavel:

\footnotetext{
"[...] veja que, mudando somente os rostos dos homens e as cores exteriores, as mesmas coisas sempre retornam, e não vemos acontecimento algum que em outros tempos não se tenha visto. Mas o mudar de nomes e figuras das coisas faz com que somente os prudentes as reconheçam: por isso é boa e útil a história: porque te coloca adiante e te faz reconhecer e rever aquilo que diretamente não conheceu ou viu" (Maquiavel, 1989:298, ênfases e tradução do autor).
}

Na máxima 76 dos Ricordi, ele apresenta argumentos similares, ao dizer que "tudo aquilo que foi no passado e é no presente será ainda no futuro; mas os nomes e as aparências das coisas mudam de tal maneira que quem não tem bom olho não as reconhece" (Guicciardini, 1995:83, ên- 
fases do autor). No Dialogo del Reggimento de Firenze, há uma passagem em que o personagem Bernardo del Nero reproduz os mesmos pontos de vista:

\begin{abstract}
“E, assim, tudo aquilo que foi no passado, parte é no presente, parte será em outros tempos e algum dia retornará a ser, mas sobre aspectos exteriores diferentes e várias cores, de modo que quem não possui os olhos muito bons o toma por novo e não o reconhece; mas quem tem a vista aguda e que se aplica a distinguir cada caso, e considera quais são as diversidades substanciais e quais são aquelas que importam menos, facilmente o reconhece, e com o cálculo e medida das coisas passadas pode calcular e medir o futuro" (Guicciardini, 1994:36, ênfases e tradução do autor).
\end{abstract}

Guicciardini não só afirma, no Dialogo, os mesmos princípios sustentados na carta endereçada a Maquiavel e na máxima 76 dos Ricordi, como defende a possibilidade de "calcular e medir" o futuro, desde que o analista tenha a "vista aguda", atenta às "diversidades substanciais". Ora, na correspondência ele estabelece relação bastante similar: "o mudar de nomes e figuras das coisas faz com que somente os prudentes as reconheçam". Se relacionarmos as três passagens, torna-se possível dizer que, para o autor, ter a "vista aguda" implica notar o que está para além das "mudanças de nomes e figuras". Também na Oratio Consolatoria, Guicciardini se vale da metáfora dos olhos penetrantes: "Alcançam fins vãos ou a superfície das coisas aqueles que, sem leitura ou experiência, não possuem olhos penetrantes" (Guicciardini, 1993:115, ênfases e tradução do autor).

Tais asserções só podem fazer sentido se pensadas em função de uma concepção cíclica do tempo, ainda que assimétrica - assimétrica porque não se trata do "eterno retorno do mesmo", mas de tendências de estabilidade ou alternância de padrões gerais, análogos aos ciclos naturais e associados tanto a certos princípios cosmológicos quanto à idéia de uma natureza humana permanente, sem que impliquem, todavia, a repetição dos accidenti (Mazzarino, 2004:412-461). Ao separar analiticamente o substancial do acidental, os prudentes, donos de "olhos agudos e penetrantes", habilitam-se a desvendar os meandros do que "foi, é e será".

Na máxima de número 6 dos seus Ricordi, porém, Guicciardini recomenda uma postura zelosa na formulação de tais juízos: 
"[...] é um grande erro falar das coisas do mundo indistinta e absolutamente e, por assim dizer, por regola: porque quase todas têm distinções e exceções pela variedade das circunstâncias, as quais não se podem estabelecer com uma mesma medida: e estas distinções e exceções não se encontram escritas nos livros, mas é preciso que a discrezione as ensine" (Guicciardini, 1995:53, ênfases do autor).

A dessemelhança mostra-se aos olhos de todos; aqueles que têm a "vista aguda", porém, são capazes de perceber o que está para além das "cores" diferentes. Por esta razão, Guicciardini classifica, em passagem do Dialogo citada anteriormente, as diversidades em dois tipos: "substanciais" e "acidentais". As substanciais são aquelas relacionadas à imutabilidade da natureza humana, ao que "foi, é e será", aos padrões recorrentes de conduta e motivações humanas gerais, àquilo que é desigual apenas por aparência externa. Já as diversidades acidentais - accidenti - dizem respeito ao sentido mortal dos homens e das suas produções, o fortuito, tudo aquilo que está sujeito ao acaso e à Fortuna: "Quem considerar bem, não pode negar o grande papel que tem a Fortuna nas coisas humanas, porque se verifica que estas recebem a toda a hora impulsos de acidentes fortuitos" (Guicciardini, 1995:65, máxima 30, ênfase do autor).

Neste ponto, cabe ressaltar a diferenciação feita, na anteriormente citada máxima de número 6 dos Ricordi, entre o falar do mundo por regola e o falar do mundo com discrezione. Guicciardini critica, aí, os discursos que, em nome de um parlare generalmente, deixam de considerar as contingências dos assuntos humanos; estes falam da realidade por regola, costume, sem reflexão, incapazes que são de agir com discrezione, ou seja, com discernimento. Também no discurso Del Governo di Firenze dopo la Restaurazione de' Medici nel 1512, o autor condena o "falar em geral e com uma mesma regola", opondo a este o "falar geralmente com distinzione" (Guicciardini, 2000b:44, tradução do autor). A possibilidade de tecer afirmações de caráter generalizante não é negada; estas, todavia, devem ser urdidas com discernimento e zelo. Ou seja: o analista precisa atentar a cada caso, e então separar o que é substancial, recorrente, do acidental e fortuito.

\footnotetext{
"As coisas futuras são tão falazes e submetidas a tantos acidentes [accidenti], que o mais das vezes mesmo os mais sábios se enganam; e quem anotasse as suas opiniões, máxime nos particulares das coisas - porque nas gerais advinham com freqüência -, verificaria que há pouca diferença
} 
entre eles e os que são tidos como menos sábios [...]" (Guicciardini, 1995:61, máxima 23, ênfases do autor).

Mesmo os sábios que se propõem a falar do futuro em seus detalhes sujeitam-se a cometer graves equívocos. Porém, aqueles sábios que buscam discutir as coisas "gerais advinham com freqüência", podendo planejar com alguma precisão as ações presentes. Deve-se notar que nesta máxima Guicciardini se refere aos sábios, pessoas capazes de olhar com discrezione para as "coisas do mundo": esta se revela, assim, um elemento crucial do olhar guicciardiniano para a política, exatamente por constituir um predicado decisivo de analistas e governantes (Sasso, 1984:13).

Seguindo este raciocínio, penso que a famosa máxima 117 dos Ricordi, em que Guicciardini critica o recurso excessivo aos exemplos, não deva ser interpretada como uma condenação veemente das comparações entre situações diferenciadas, mas como a exigência de rigor analítico em tais aproximações: "É falacíssimo julgar pelos exemplos porque, se não são semelhantes em tudo e por tudo, não servem, pois cada mínima variedade no caso pode ser causada de enorme variação no efeito. Para sermos capazes de discernir estas variedades, quando não são pequenas, devemos ter olhos bons e perspicazes" (Guicciardini, 1995:101, ênfases do autor).

Note-se que Guicciardini não nega a possibilidade de estabelecer juízos eficientes a partir de analogias. Ele defende, isto sim, o imperativo da discrezione, dos "olhos bons e perspicazes", especialmente quando as variedades entre passado e presente se mostram significativas. Se não forem estabelecidas com discernimento, as analogias constituídas no recurso a exemplos serão quase sempre falaciosas, porque rasas, desatentas à diversidade dos "nomes e cores" e aos elementos estáveis por trás das oscilações da realidade.

A discrezione permite, assim, a distinção da "qualidade das pessoas, dos casos e dos tempos". Ela não opera com "regra indistinta e fixa" (idem:131, máxima 186): a flexibilidade e a capacidade de adaptação são suas propriedades básicas, uma vez que somente o olhar agudo para os fatos singulares, ao penetrar a substância das "coisas do mundo", torna possível o estabelecimento de um juízo eficaz para a análise da ação política. Tal capacidade deve-se, primordialmente, a uma "prudência natural", a qual pode ser aprimorada pela experiência prática e pela educação retórica, especialmente pelo estudo das "histórias 
antigas e modernas" (Kahn, 1985). Diz Guicciardini: "que ninguém confie tanto na prudência natural ao ponto de persuadir-se de que esta basta sem a experiência como acessório, porque todos os que lidaram com negócios, ainda que prudentíssimos, puderam verificar que com a experiência se chega a fazer muitas coisas, o que não é possível apenas com o talento natural" (1995:55, máxima 10).

O olhar atento para "cada caso" deve alicerçar, assim, a separação analítica entre "diversidades substanciais" e os accidenti: a atenção ao particular se afirma, deste modo, como a "porta" de acesso ao recorrente, desde que operada de maneira cuidadosa. Com "olhos penetrantes", o analista se habilita a perceber que "quase todos os mesmos provérbios ou semelhantes, ainda que com palavras diferentes, encontram-se em todas as nações; e a razão é que os provérbios nascem da experiência, ou seja, da observação das coisas, as quais são as mesmas ou semelhantes em todos os lugares" (idem:55, máxima 12). Deste modo, torna-se possível atestar a existência, em Guicciardini, de dois planos analíticos do real, e digo analíticos porque eles só se revelam dissociáveis por meio de abstração conceitual. Ao observador atento da realidade, apenas as "diversidades substanciais" interessam para a urdidura de juízos políticos inequívocos. Quanto aos accidenti, ainda que se façam presentes a todo o momento, não podem ser previstos; ainda assim, devem ser examinados com o maior cuidado e rigor, uma vez que, ao primeiro olhar, é muito difícil, mesmo para o prudente, distingui-los das "diversidades substanciais". Os assuntos humanos, como afirma Guicciardini no Dialogo pela voz de Bernardo del Nero,

“[...] possuem variações diárias, segundo o andamento do mundo, e as decisões a serem tomadas têm por fundamento quase sempre a conjuntura, e de um pequeno movimento dependem com muita freqüência as coisas da maior importância, e dos princípios pouco notados nascem muitos efeitos de conseqüências gravíssimas. Por isso é necessário que o governante seja muito prudente, dedicando atenção aos mínimos 'accidenti', e pese bem tudo aquilo que pode acontecer, esforçando-se em evitar de início e excluir, na medida do possível, o poder do acaso e da Fortuna" (Guicciardini, 1994:96, ênfases e tradução do autor).

O prudente não pode desconsiderar o poder da Fortuna e o papel do acaso nos assuntos humanos. Cada acontecimento e suas condições, cada nova situação e seus desenlaces, devem ser estudados, analisados e calculados com extremo cuidado, de modo que os "mínimos acidentes" possam ser isolados e seus possíveis efeitos, distinguidos e exami- 
nados. Aqui, o alto grau de segurança dos juízos formulados a partir do exame das "diversidades substanciais" dá lugar à medida do possível, juízos prováveis, não-necessários, mas nem por isso pouco eficientes. A divisão dos argumentos em possíveis ou necessários é questão amplamente discutida em tratados clássicos de retórica. No De Inventione, Cícero (1997:44), seguindo Aristóteles, sustenta que "a argumentação é qualquer tipo de procedimento concebido que demonstre que algo é provável ou necessário".

Assim, embora o conhecimento prudencial da política possa, muitas vezes, constituir juízos necessários - aqueles formulados a partir do exame das "diversidades substanciais" -, estes devem ser complementados pelos juízos prováveis, formulados pelo exame atento dos accidenti e dos movimentos da Fortuna - entendida, segundo Santoro, como "complexo de circunstâncias, de eventos, que condicionam de modo imprevisível o agir do indivíduo" (1978:160). A crítica de Guicciardini à astrologia tem por base precisamente esta distinção entre conhecimento seguro e provável: os astrólogos tentam, segundo Guicciardini, deliberar com segurança sobre o fortuito, o acaso. Para o escritor florentino, não se pode prever o futuro com estes meios: "pensar em saber o futuro por este caminho é um sonho" (1995:141, máxima 207). Somente o analista prudente pode afirmar com boa margem de acerto o "vir a ser", pois que este "foi" e "é"; e mesmo o prudente não pode tecer generalizações sobre os accidenti, na medida em que estes, por estarem sob a jurisdição da Fortuna, não dizem respeito ao recorrente, mas ao contingente $^{3}$. Deste modo, a formulação de juízos prudentes deve levar em conta, segundo Guicciardini, tanto os argumentos necessários quanto os prováveis, que devem ser considerados de acordo com a questão analisada.

\section{O PROBLEMA DA CORRUPÇÃO}

Passo agora à discussão dos princípios cosmológicos que alicerçam este tipo de olhar prudencial para a realidade - questão diretamente relacionada à concepção circular-assimétrica do tempo, aludida anteriormente. Trata-se de uma questão crucial para a compreensão do problema da corrupção, uma vez que o discurso político de Guicciardini assim como o de Maquiavel - se volta em grande medida para a tentativa de elaborar uma teoria da ação capaz de amenizar ou reverter a corrupção dos costumes - expansão dos vícios e contração das virtudes -, 
processo este associado à própria natureza, seus ciclos e à relação do homem com tais tendências naturais.

Na máxima 189 dos Ricordi, Guicciardini afirma que "todas as cidades, os Estados, todos os reinos são mortais; todas as coisas, natural ou acidentalmente, terminam e findam alguma vez" (Guicciardini, 1995:131-132, ênfases do autor). Nas Considerazioni intorno ai Discorsi del Machiavelli, ele pondera que também a religião, as artes e os estados estão sujeitos a tais alterações cíclicas (Guicciardini, 2000d:379). Como se pode ver, Guicciardini enfatiza especialmente o problema da degradação dos costumes e das formas de governo, assim como o faz Maquiavel nos Discorsi. No Discorso di Logrogno, ele afirma que "a corrupção que há no mundo não é de hoje; dura já por muitos e muitos séculos, o que atestam os escritores antigos que tanto detestaram e falaram contra os vícios de seus tempos" (Guicciardini, 2000a:40, tradução do autor).

Tudo no mundo passa por estágios de ascensão e queda. Este é um princípio natural, e não só o homem "singular" se sujeita aos ciclos naturais; mesmo os costumes e formas de governo não são estáveis, como haviam atestado Heródoto e Políbio. Afirma Guicciardini, na Storia d'Italia: "não constitui vergonha para as cidades ilustres se após muitos séculos caem finalmente em servidão, porque era fatal que todas as coisas do mundo fossem submetidas à corrupção" (1988, livro II, cap. 1:151, tradução do autor). Em um paradoxo aparente, este princípio universal da decadência reforça a idéia de uma natureza humana estável (Maravall, 1986:351): os homens morrem e nascem, suas cidades se expandem e retraem, as virtudes e os vícios se alternam, e ainda assim os que lêem as histórias legadas pelos antigos nelas vêem refletidas as mesmas preocupações e anseios similares. Em períodos de decadência, os vícios adquirem realce, de modo que o homem, naturalmente bom, deixa-se levar por cupidez ou interesses alheios à verdadeira glória e honra:

\footnotetext{
“Todos os homens são por natureza mais inclinados ao bem que ao mal, e desde que outro aspecto não os conduza a direção contrária, não há ninguém que não faça voluntariamente mais o bem que o mal; mas a natureza dos homens é tão frágil e tão freqüentes no mundo as ocasiões que convidam ao mal que os homens deixam-se facilmente desviar do bem. E por isso os sábios legisladores encontraram os prêmios e as penas: outras coisas não fizeram que manter os homens firmes na inclinação natural deles" (Guicciardini, 1995:107, máxima 134).
} 
Para Guicciardini, aquele que "por natureza seja inclinado a fazer voluntariamente mais o mal que o bem [...] não é homem, mas animal ou monstro, já que lhe falta a inclinação que é natural de todos os homens" (idem:107, máxima 135).

Eugenio Garin (1997:36) afirma que a idéia de um "declínio inevitável" das coisas humanas era um lugar-comum no pensamento renascentista, assim como a crença em ressurgimentos. Este juízo fundava-se em uma concepção de realidade centrada na distinção entre as coisas celestes, imutáveis e perfeitas, e as coisas terrenas, sujeitas à corrupção e aos ciclos naturais. Por esta lógica que dirigia o universo, entendia-se que as coisas inferiores eram governadas pelas superiores, e tudo o que ocorria no mundo sublunar - mudanças das estações, nascimento e morte das plantas e animais - era regido pela perfeição dos céus e das estrelas. O homem e suas produções - governos e costumes, por exemplo -, como partes do mundo sublunar, submetiam-se aos mesmos princípios naturais de decadência e regeneração.

Estas questões, relativas à posição do homem diante da natureza, e desta em relação à imutabilidade dos "céus", eram abordadas de diversas formas pelos autores políticos do período. Maquiavel, por exemplo, alicerça boa parte das reflexões centrais dos Discorsi nestes princípios cosmológicos, como demonstra A. J. Parel. A "concepção maquievaliana da história" está calcada, nas palavras de Parel, na premissa de que "todos os movimentos no mundo sublunar, sejam naturais ou humanos, são pensados como dependentes dos movimentos que emanam dos céus, dos planetas e das estrelas" (1993:254, tradução do autor). De modo análogo, o raciocínio inverso mostrava sua validez: a conexão entre homem e mundo natural permitia que alterações súbitas e violentas nos negócios humanos fossem entendidas como causas de distúrbios severos na "ordem da natureza". Guerras, invasões, mudanças de governo ou de formas políticas: tais rupturas suscitavam fenômenos alheios aos movimentos regulares do mundo, como marcas da íntima conexão entre homem e natureza. Se as oscilações desta afetavam todas as pessoas, do mesmo modo os distúrbios importantes concernentes aos assuntos humanos incidiam na agitação provisória da natureza. Os fenômenos anormais se davam a ler como sinais evidentes, marcas da inscrição na natureza das desordens concernentes aos homens, como guerras sangrentas e mudanças repentinas de governo. Diz Foucault acerca daquilo que denomina "epistème do século XVI": "Não há semelhança sem assinalação. O mundo do similar só pode ser 
um mundo marcado" (1999:36). Tais marcas apresentam-se como indícios à espera de decifração: "o saber das similitudes funda-se na súmula de suas assinalações e na sua decifração" (ibidem). Nas Storie Fiorentine, Guicciardini afirma que a morte de Lorenzo de' Medici teria sido precedida de diversos eventos bizarros, prenúncios das sérias crises que estavam por vir:

“As graves conseqüências desta morte foram anunciadas por diversos
presságios: pouco tempo antes, apareceu um cometa; ouviam-se uivar
os lobos; uma mulher enlouquecida em Santa Maria Novella gritou que
um touro com chifres de fogo incendiava toda a cidade; alguns leões
brigaram entre si, e um deles, belíssimo, foi morto pelos outros; e por
último, um ou dois dias antes de sua morte, durante a noite, um raio
atingiu a cúpula de Santa Liperata, e fez rolar algumas pedras enormes,
as quais caíram próximas à casa dos Médici [...] (Guicciardini, 1998:172,
tradução do autor).

Em Storia d'Italia, Guicciardini dedica um capítulo inteiro a acontecimentos estranhíssimos que, segundo ele, anunciaram, pouco antes da invasão dos franceses em 1494, a calamità que acometeria em seguida a Península Itálica: "aqueles que dizem ter notícias das coisas futuras, ou por ciência ou por sopro divino, afirmavam com as mesmas vozes o aparecimento de muitas e freqüentes mudanças, acidentes muitos estranhos e horrendos que por muitos séculos não tinham lugar em parte alguma do mundo" (1988:81, livro I, cap. 9, tradução do autor). Este momento terrível e decisivo para sua geração era vaticinado, segundo ele, por situações aterrorizantes, como a a parição de três sóis, em plena noite, na cidade de Puglia. Em Arezzo, homens armados teriam sido vistos vagando pelos céus, montados em seus cavalos; até mesmo o fantasma do rei Ferdinando teria aparecido a um cirurgião da corte napolitana, a quem relatara a inutilidade de qualquer tentativa de resistir às invasões francesas (idem:133, livro I, cap. 18).

Ao mobilizar "eventos muito estranhos e horrendos" em sua história, Guicciardini está em pleno acordo com as tradições historiográficas dos antigos e dos humanistas, em que estas referências são abundantes. Tais situações asseguram retoricamente força persuasiva aos relatos moralizantes, por enfatizarem tanto os perigos do vício desmedido quanto a necessidade do equilíbrio moral via virtude. $\mathrm{O}$ fato de se tratar de uma tópica retórica recorrente em histórias da Antiguidade e do Renascimento reforça as oposições vício/virtude e desmedida/harmonia, associadas tanto à corrupção natural quanto à acentuação da degradação 
provocada por ações desmesuradas. Daí a relação entre as súbitas alterações na ordem das "coisas do mundo" - derrubadas de reis, mudanças de governos, pestes etc. - e a desarmonia da ordem natural. Na medida em que se pode afirmar que os vícios eram então percebidos como elementos ativadores da aceleração dos processos naturais de corrupção, concebia-se analogamente que ações virtuosas poderiam incidir na reversão, mesmo que parcial, destes movimentos naturais de degradação, tendências que, todavia, podiam ou não se realizar.

Como afirma Giacomo Marramao (1995:39), acostumamo-nos a pensar o tempo dicotomicamente: de um lado, o tempo cristão, linear; de outro, o tempo pagão, cíclico. Estas metáforas geométricas muitas vezes impedem a percepção aguda das singularidades de certas lógicas, como a que vem sendo discutida aqui. Diz Maquiavel, nos Discorsi: "todas as coisas do mundo em qualquer tempo possuem correspondência [riscontro] com os tempos antigos. Isto acontece porque, tendo sido realizadas pelos homens, que têm e terão sempre as mesmas paixões, é necessário que surtam o mesmo efeito" (Maquiavel, 2000:450-451, livro III, cap. 43, tradução do autor). Aqui, a palavra-chave é riscontro, correspondência. As coisas não se repetem da mesma forma: elas são análogas, comparáveis, porém diferentes. Como não são exatamente idênticas, torna-se possível intervir no sentido da inversão ou aceleração dos ciclos de queda, desde que o observador da realidade seja capaz de perceber tais movimentos. Na opinião de Maquiavel, seria possível reverter o movimento de corrupção; Guicciardini, por sua vez, mostra-se cético quanto a isso. Mesmo assim, dedica boa parte de suas reflexões ao problema da degradação dos costumes e dos valores republicanos, com a finalidade de encontrar $\mathrm{Cu}$ ras parciais capazes de amenizar estes males. De todo modo, pode-se dizer que a teoria guicciardiniana da ação política não possui um campo de intervenção tão abrangente quanto a teoria maquiaveliana, calcada na possibilidade de reversão completa do estado de corrupção das "coisas do mundo" pelo resgate da antiga virtus romana.

Em suas Considerazione sobre os Discorsi de Maquiavel, Guicciardini procura refutar a tese da estabilidade da "substância" virtù: "é verdadeiro que, ou por influência dos céus ou por algum arranjo oculto, ocorre que, em certas eras, não só em uma província, mas universalmente em todo o mundo, há mais virtù ou mais vício que em outra era [...]" (Guicciardini, 2000d:379, tradução do autor). Para ele, o mundo pós-1494 era marcado por muitos vícios e pouca virtù. A divergência pode parecer tola, mas é de fato decisiva, pois que delimita os horizontes distintos de ação, assim 
como o alcance do método de cada um. Para Maquiavel, o que estava em jogo era a "imitação" da virtù dos antigos, enquanto Guicciardini via a corrupção e a decadência como dados inevitáveis, conquanto passíveis de atenuação. Daí a crítica dirigida àqueles que a todo o momento recorrem aos romanos, em busca de exemplos para a ação presente. A seu ver, seria preciso "ter uma cidade como era a deles, e depois governar-se segundo aquele exemplo, o qual, para quem tem qualidades desproporcionais, é tão desproporcional quanto querer que um asno corra como um cavalo" (Guicciardini, 1995:97, máxima 110). Trata-se, segundo Vittorio de Caprariis (1993:90), de uma "atitude madura diante do fato históri$\mathrm{co}^{\prime}$, marca de "uma tentativa de aprofundamento deste, um desejo de observá-lo em toda a sua complexidade", efetiva condenação do uso não refletido do passado.

\section{UM MÉTODO PRUDENCIAL DE ANÁLISE DA POLÍTICA}

Se a imitação da virtù não poderia, para Guicciardini, orientar as ações presentes, o que fazer contra a corrupção? De que maneira o homem poderia intervir ativamente junto aos movimentos de queda dos valores e das instituições? A resposta a esta questão passa pelo uso específico de um topos recorrente entre os autores humanistas, e que remete à filosofia política clássica: a prudentia, ou, em sua versão toscana, prudenzia. O escritor florentino vale-se de metáforas médicas que ajudam a esclarecer acerca dos objetivos de seu procedimento analítico: a demarcação de um conjunto de ações adequadas, capazes de levar ao estabelecimento de curas parciais para os males da cidade. Mesmo que estas ações não visem à reversão completa dos ciclos de queda, elas podem incidir na neutralização dos efeitos da corrupção. "Os médicos prudentes e experientes", diz Guicciardini,

\footnotetext{
"[...] em nada usam zelo mais exato que ao conhecer a natureza do mal, ao perceber os traços, a qualidade e todos os acidentes, para resolver-se, a partir destes fundamentos, qual deve ser o tratamento [reggimento] do enfermo, de que sorte e em que tempo se deve dar a ele os remédios; não se observando bem estes procedimentos [...], ele dará remédios não proporcionais ao mal, ou contrários à compleição do enfermo; o que poderia gerar a morte e ruína total do doente" (2000b:43, ênfases e tradução do autor).
}

Cabe notar que a palavra reggimento, utilizada aqui no sentido de tratamento, também possui, na língua toscana do quinhentos, a acepção de 
governo. É preciso que o "médico prudente" conheça a natureza dos males que afligem o paciente para que sua receita seja eficaz. Logo a seguir, Guicciardini vai mais além em sua comparação entre a prudenzia do médico e aquela do governante:

"E como do fato de um enfermo ser bem ou mal medicado se pode chegar a um argumento potente sobre sua melhora ou sua morte, o mesmo acontece no governo de um 'stato', porque sendo conduzido prudentemente e proporcionalmente, se pode crer e esperar bons efeitos; sendo conduzido de outra forma e mal governado, em que se pode crer senão na sua destruição?" (idem:44, ênfases e tradução do autor).

As analogias empregadas por Guicciardini são bastante reveladoras: a medicina renascentista não trabalhava com a noção de curas totais. $\mathrm{O}$ médico era visto como um "administrador" dos males do corpo, capaz de proporcionar bem-estar, sobrevida, mas não soluções completas. Da mesma forma, o discurso político de Guicciardini visava à indicação dos meios capazes de propiciar a sobrevida das cidades e seus ordenamentos, por intermédio da atenuação dos malefícios da corrupção. Esperava-se tanto dos bons médicos quanto dos bons governantes a capacidade de observar as verdadeiras causas do mal atuante - no corpo ou no stato -, para assim aplicar os melhores remédios, antecipando e antevendo os efeitos negativos das doenças. Aqui, um ponto central é a denominação dada àqueles médicos e governantes que possuem a "vista aguda": a estes, Guicciardini chama de prudentes.

Antes de avaliar a extensão desta novidade no entendimento da prudenzia - a capacidade de predição com alguma segurança dos efeitos das ações, com base em argumentos prováveis ou necessários, de modo que o espectro de falibilidade inerente às "coisas do mundo" pudesse ser profundamente reduzido -, cabe tecer alguns comentários sobre as tradições com que Guicciardini lidava no tratamento desta questão. Como argumentei anteriormente, o tema da prudência era caro tanto a Platão quanto a Aristóteles, porém em sentidos distintos. Se, para o ateniense, a phrónesis constitui o equivalente a uma ciência da política, em Aristóteles ela é vista como virtude intelectual, ligada à reflexão sobre o contingente, capaz de orientar o homem a agir de acordo com as virtudes morais. Cícero, por sua vez, defende que a prudentia ensina a agir, em total concordância com as demais virtudes cardeais e principescas. Quanto à tradição escolástica, cabe dizer que opõe pela primeira vez prudentia e Fortuna. Este "remédio da prudência contra a Fortuna", típico do pensamento escolástico, "valia-se de consentir ao homem reconhecer e 
medir o caráter provisório e vão dos bens exteriores, e de distinguir o bem e o mal na conduta prática do viver" (Santoro, 1978:47, tradução do autor). Tomás de Aquino caracteriza a prudentia como a mais importante dentre as virtudes necessárias ao bem-viver, aquela que aplica a "reta razão ao agir" (Aquino, 2005:8, questão 47, art. 4). Ele enfatiza também seu lado intelectual, e faz da prudentia uma disposição-chave para o conhecimento simultâneo dos princípios universais e particulares, orientada pela distinção cristã entre bem e mal.

Entre os autores do chamado "humanismo cívico", a polaridade volta a se dar entre Fortuna e virtus. Nesse sentido, a prudentia era vista como virtude essencial ao retto agire (Santoro, 1978:52), ou, como escreve o autor anônimo da Retórica a Herênio - a qual, juntamente com o tratado ciceroniano sobre a invenção retórica, era considerada o texto-base da formação ético-retórica humanista (Ward, 1983) -, "prudência é a destreza que pode, com certo método, discernir o bem e o mal" (autor desconhecido, 2005, livro III, cap. 3), através da comparação entre vantagens e desvantagens, do conhecimento "dos meios ou dos métodos" para executar uma ação, ou o aconselhamento de "um procedimento de cuja história tenhamos lembrança por tê-la presenciado ou ouvido contar" (idem, livro III, cap. 4).

Esta rápida incursão tem por objetivo apontar algumas heranças com que Guicciardini lidava: ao opor Fortuna e prudenzia, ele parece retomar, ao menos em parte, a forma com que os escolásticos tratavam a questão - de Tomás de Aquino, especificamente, o autor recupera a noção de que esta seria capaz de discorrer sobre o particular e o universal, embora não no sentido de uma moral cristã. $\mathrm{O}$ direcionamento a um retto agire, típico do "humanismo cívico", também se faz presente, ainda que dissociado do imperativo ético da justiça. Existem, porém, algumas diferenças cruciais: contrariamente a Cícero e aos humanistas, Guicciardini não subsume a prudência à justiça. A primeira consiste, para o escritor florentino, em uma disposição prática. Nesse sentido, Guicciardini parece trabalhar com um modelo similar ao da phrónesis de Aristóteles, que relaciona a prudência à análise efetiva da contingência, sem que esta se distancie, todavia, da noção de bem comum. Como argumentei, o estagirita reconhecia a figura do phrónimos, o prudente, como o homem habilitado a tomar decisões corretas no âmbito da pólis. Nesse sentido, pode-se dizer que Guicciardini reivindica para si o papel do prudente escrevendo sobre a prudenzia. 
Deve-se notar, contudo, que o entendimento guicciardiniano de prudenzia não pode ser inteiramente englobado pelo modelo aristotélico: para o escritor florentino, a prudenzia constitui o principal alicerce de uma forma de análise das coisas da política fundada na capacidade de antecipação, necessária ou provável, dos efeitos das ações humanas. A idéia de que a prudenzia pudesse atuar como elemento de predição não era inteiramente nova, embora não tivesse sido muito explorada pelos humanistas. Cícero, no De Officiis, afirma que uma das qualidades centrais do homem sábio e prudente consistia exatamente na capacidade de "antever as coisas futuras e, no momento crítico, resolver os problemas tomando a decisão oportuna" (Cícero, 1999, livro II, § 33). No De Inventione, o filósofo romano afirma que as partes da prudência são "[...] a memória, a inteligência e a previsão [providentia]. A memória é a faculdade que permite à mente recordar o passado; a inteligência, $\mathrm{o}$ que faz compreender os acontecimentos presentes; a previsão, o conhecimento da realização de uma coisa antes que aconteça" (Cícero, 1997, livro II, § 160, ênfase e tradução do autor).

Em Guicciardini, tal capacidade de previsão constitui um elemento decisivo do olhar prudencial para os fenômenos políticos. Por esta razão, discordo da afirmação de John Pocock de que a prudenzia, para o escritor florentino, consistiria apenas em uma "política de manobras" e precauções temerosas, sem visar à intervenção direta e à ação no mundo (Pocock, 1975:238). Diz Guicciardini, na Storia d'Italia:

“[...] não se deve confundir - como poucos observadores das propriedades, dos nomes e da substância das coisas afirmam - a timidez com a prudenzia; nem se deve reputar como sábios àqueles que, tomando por certo todos os perigos, agem como se todos fossem acontecer. Não se pode chamar de sábio ou prudente àqueles que temem o futuro mais que se deve" (1988:284, livro III, cap. 4, tradução do autor).

Ser prudente não é adotar posturas medrosas. Para Guicciardini, prudenzia implicava a capacidade de se colocar no mundo, de agir com rapidez, de tentar antecipar os efeitos das ações e decisões dos principais agentes políticos.

A experiência do homem de Estado - a qual, como diz o personagem Piero Guicciardini no Dialogo, "não se aprende nos livros dos filósofos" (Guicciardini, 1994:24, tradução do autor) -, somada ao conhecimento das histórias e à prudência natural, constituem assim os alicerces do "método prudencial" de Guicciardini, método este que será, senão negado, 
ao menos bastante problematizado em seu último escrito, a Storia d'Italia, texto marcado pelo desencantamento político e resignação diante do amplo predomínio da Fortuna. Em suas obras políticas de juventude e meia-idade, porém, as histórias são tratadas como repositórios de fatos, dos quais o analista se valerá para formular seus juízos, constituindo-se assim como aberturas para o presente de experiências alheias (Koselleck, 1985:272).

Existe, ainda, um elemento que torna possível a união entre experiência e sabedoria histórica na forma de conhecimento: a ragione. Afirma o personagem Bernado del Nero, no Dialogo: "sou daqueles que nunca me valeria da experiência, a menos que esta viesse acompanhada da ragione" (Guicciardini, 1994:45, tradução do autor). No sentido empregado, ragione indica a capacidade de articular a experiência e o conhecimento das histórias na forma de um juízo prático eficiente. Não se trata, aqui, da razão cartesiana, lógica e abstrata, que caracterizará a modernidade, mas da faculdade de estabelecer o que é ragionevole, racional porque razoável. Sobre a razão em Guicciardini, afirma Gennaro Barbuto:
"era uma razão que nascia na ágora, no confronto entre a opinião dos mais 'sábios', que se valiam dos exemplos passados da história florenti- na, mas, em particular, do caráter persuasivo da 'razão', conectada à contingência particular, sem pretensão alguma de fixar princípios ge- rais e intangíveis" (2002:36, ênfase no original e tradução do autor).

Esta forma de abordar os fenômenos políticos tem por fundamento a necessidade do exame agudo dos efeitos de cada ação, cada movimento, cada jogada dos principais agentes responsáveis pelos rumos das Repúblicas e dos principados italianos. Trata-se de um procedimento analítico que exige a consideração atenta das inúmeras vicissitudes de uma realidade sempre cambiante e das possibilidades efetivas diante de tais circunstâncias. Pode-se dizer, deste modo, que a idéia de República bem-ordenada deva ser entendida nos textos de Guicciardini como a busca de um melhor governo possível, adequado à dinâmica do seu tempo, tendo o bom governo como um horizonte regulatório ideal, a orientar criticamente o jogo a ser jogado no complexo tabuleiro da história. 


\section{Felipe Charbel Teixeira}

\section{NOTAS}

1. Existe um grande debate acerca da pertinência do emprego do conceito "humanismo cívico". Optei pelo uso, por considerá-lo delimitador de um tipo específico de humanismo, associado às reflexões retórico-políticas de chanceleres e magistrados republicanos, especialmente na Florença da primeira metade do século XV, em oposição a outros humanismos, como o neoplatônico.

2. Viroli (1992) considera Guicciardini um autor de transição, na encruzilhada entre a arte do bom governo e a arte do estado, juízo a meu ver equivocado, menos pela teleologia da análise que pelo obscurecimento da singularidade da análise guicciardiniana acerca da relação entre ideal e possível.

3. A importância do conceito de Fortuna nos escritos de Guicciardini acentua-se a partir de 1527, ano em que se dá o saque de Roma. A partir desse momento, o conceito de Fortuna exercerá um papel de destaque em seus escritos, especialmente na Storia d'Italia (Gilbert, 1984).

\section{REFERÊNCIAS BIBLIOGRÁFICAS}

Autor Desconhecido. (2005), Retórica a Herênio. São Paulo, Hedra.

AQUINO, Santo Tomás de. (2005), A Prudência. A Virtude da Decisão Certa. São Paulo, Martins Fontes.

ARISTÓTELES. (1985), Ética a Nicômacos. Brasília, Editora UnB.

AUBENQUE, Pierre. (1986), La Prudence chez Aristote. Paris, PUF.

BARBUTO, Gennaro Maria. (2002), La Politica dopo la Tempesta. Ordine e Crisi nel Pensiero di Francesco Guicciardini. Napoli, Liguori Editore.

BIGNOTTO, Newton. (2006), Republicanismo e Realismo. Um Perfil de Francesco Guicciardini. Belo Horizonte, Editora UFMG.

CíCERO, Marco Túlio. (1997), La Invención Retórica (De Inventione). Madrid, Editorial Gredos.

(1999), Dos Deveres (De Officiis). São Paulo, Martins Fontes.

CAPRARIIS, Vittorio de. (1993), Francesco Guicciardini. Dalla Politica alla Storia. Napoli, Società Editrice Il Mulino.

EISENBERG, José. (2003), A Democracia depois do Liberalismo. Rio de Janeiro, Relume Dumará.

FOUCAULT, Michel. (1999), As Palavras e as Coisas. São Paulo, Martins Fontes.

GARIN, Eugenio. (1997), O Zodíaco da Vida: A Polêmica sobre a Astrologia do Século XIV ao Século XVII. Lisboa, Editorial Estampa. 


\section{O Melhor Governo Possível: Francesco Guicciardini e o Método Prudencial...}

GILBERT, Felix. (1984), Machiavelli and Guicciardini. New York/London, W.W. Norton \& Company.

GUICCIARDINI, Francesco. (1988), Storia d'Italia. Roma, Garzanti Editore.

. (1993), Consolatoria, Acusatoria, Defensoria. Autodifesa di un Politico. Bari, Laterza.

. (1994), Dialogo del Reggimento di Firenze. Torino, Bollati Boringhieri.

. (1995), Ricordi/Reflexões. São Paulo, Hucitec/Istituto Italiano di Cultura/Instituto

Cultural Ítalo-Brasileiro.

. (1998), Storie Fiorentine. Milano, Biblioteca Universale Rizzoli.

(2000a), "Del Modo di Ordinare il Governo Popolare (Discorso di Logrogno)", in

G. Barbuto (org.), La Liberta Moderata. Torino, La Rosa Editrice.

. (2000b), "Del Governo di Firenze dopo la Restaurazione de' Medici nel 1512", in

G. Barbuto (org.), La Liberta Moderata. Torino, La Rosa Editrice.

. (2000c), "Del Modo di Assicurare lo Stato alla Casa de' Medici", in G. Barbuto

(org.), La Liberta Moderata. Torino, La Rosa Editrice.

. (2000d), Considerazioni intorno ai Discorsi del Machiavelli. Torino, Einaudi.

KAHN, Victoria. (1985), Rhetoric, Prudence, and Skepticism in the Renaissance. Ithaca/ London, Cornell University Press.

KOSELLECK, Reinhart. (1985), Futures Past. On the Semantics of Historical Time. Massachusetts, MIT.

MAQUIAVEL, Nicolau. (1989), Lettere a Francesco Vettori e a Francesco Guicciardini. Milano, Biblioteca Universale Rizzoli.

. (2000), Discorsi sopra la Prima Deca di Tito Livio. Torino, Einaudi.

MACINTYRE, Alasdair. (2001), Justiça de Quem? Qual Racionalidade? São Paulo, Edições Loyola.

MARAVALL, José Antonio. (1986), Antiguos y Modernos. Madrid, Alianza Editorial.

MARRAMAO, Giacomo. (1995), Poder e Secularização. As Categorias do Tempo. São Paulo, Editora Unesp.

MAZZARINO, Santo. (2004), Il Pensiero Storico Classico. Roma-Bari, Laterza, vol. 3.

PAREL, Anthony J. (1993), “The Question of Machiavelli's Modernity”, in T. Sorell (org.), The Rise of Modern Philosophy. The Tensions Between the New and Traditional Philosophies from Machiavelli to Leibniz. Oxford, Clarendon Press.

PETTIT, Philip. (1997), Republicanism: A Theory of Freedom and Government. Oxford, Clarendon.

PLATÃO. (1980), “O Político", in Diálogos. Belém, UFPA, vol. X.

POCOCK. J. G. A. (1975), The Machiavellian Moment. Princeton/London, Princeton University Press.

RIDOLFI, Roberto. (1967), The Life of Francesco Guicciardini. London, Routledge and Kegan Paul. 
SANTORO, Mario. (1978), Fortuna, Ragione e Prudenza nella Civiltá Letteraria del Cinquecento. Napoli, Liguori Editore.

SASSO, Gennaro. (1984), Per Francesco Guicciardini. Quattro Studi. Roma, Istituto Palazzo Borromini.

SKINNER, Quentin. (1999), As Fundações do Pensamento Político Moderno. São Paulo, Companhia das Letras.

. (2002), Visions of Politics. Cambridge, Cambridge University Press, vol. II.

VIROLI, Maurizio. (1992), From Politics to Reason of State. The Acquisition and Transformation of the Language of Politics 1250-1600. Cambridge, Cambridge University Press.

WARD, John O. (1983), "Renaissance Commentators on Ciceronian Rhetoric", in J. J. Murphy (org.), Renaissance Eloquence. Studies in the Theory and Practice of Renaissance Rhetoric. Berkeley/Los Angeles/London, University of California Press.

WOLFF, Francis. (2001), Aristóteles e a Política. São Paulo, Discurso Editorial.

\begin{abstract}
The Best Possible Government: Francesco Guicciardini and the Prudential Method of Political Analysis

This article analyzes the basis of the prudential method of political analysis developed by $16^{\text {th }}$ century Florentine statesman and writer Francesco Guicciardini. According to the article, the prudential method is based on an analytical distinction between "substantial diversities" and "accidental diversities" in human things, allowing the prudent analyst to weave arguments (necessary or probable, respectively) for reality, armed with discrezione and a "penetrating gaze" - the result of a combination of "natural prudence", experience in public affairs, knowledge of "ancient and modern history", and practical reason. The method constitutes the underpinnings for Guicciardini's reflections on political decision-making and possibilities for transforming the reggimento (government) of the city of Florence.
\end{abstract}

Key words: prudence; republicanism; good government; Guicciardini 
O Melhor Governo Possível: Francesco Guicciardini e o Método Prudencial...

\section{RÉSUMÉ}

Le Meilleur Gouvernement Possible: Francesco Guicciardini et la Méthode "Prudentielle" d'Analyse de la Politique

Dans cet article, on examine les fondements de la méthode "prudentielle" d'analyse de la politique développée par Francesco Guicciardini, homme d'état et écrivain florentin du XVI ${ }^{\mathrm{e}}$ siècle. On montre que cette méthode part d'une distinction analytique entre "diversités substantielles" et "diversités accidentelles" des choses humaines, laquelle permet de tisser des arguments nécessaires ou probables, respectivement, à l'analyste prudent de la réalité, doté de discrezione et d'un "regard pénétrant" - fruit de l'association entre "prudence naturelle", expérience dans les affaires publiques, large connaissance des "histoires anciennes et modernes" et raison pratique. Un telle méthode constitue la base des réflexions de Guicciardini en ce qui concerne la prise de décisions politiques et les possibilités de transformation $\mathrm{du}$ reggimento (gouvernement) de la ville de Florence.

Mots-clé: prudence; républicanisme; bon gouvernement; Guicciardini 